\title{
CLÍNICA E HEMATOLOGIA DE Bos indicus, Bos taurus e Bubalus bubalis INOCULADOS COM OOCISTOS DE Toxoplasma gondii (APICOMPLEXA: TOXOPLASMATINAE)
}

\author{
CLINICAL AND HAEMATOLOGY OF Bos indicus, Bos taurus AND Bubalus bubalis \\ INOCULATEAD WITH OOCYSTS OF Toxoplasma gondii (APICOMPLEXA: \\ TOXOPLASMATINAE)
}

\author{
Francisco Carlos Rodrigues de Oliveira ${ }^{1}$ Alvimar José da Costa ${ }^{2}$ \\ Gustavo Adolfo Sabatini ${ }^{3}$
}

RESUMO

Três animais de cada espécie (Bos indicus, Bos taurus e Bubalus bubalis) foram inoculados, via oral, com 2,0 $10^{5}$ oocistos de Toxoplasma gondii. Seis outros animais, dois de cada espécie, foram mantidos como testemunhas. As alterações clínicas surgidas a partir do $3^{\circ}$ dia após inoculação (DAI) foram: hipertermia, taquicardia, taquipnéia, anorexia, prostração, corrimento nasal e lacrimejamento. Estes sinais foram mais evidentes nos taurinos, espécie que apresentou, ainda, diarréia, fotofobia e conjuntivite. Foi possível isolar T. gondii da corrente sangüínea em todas as espécies. Nos taurinos, a partir do $5^{\circ}$ DAI até o final do experimento, o parasito foi isolado de todas as amostras de sangue colhidas semanalmente, com exceção do $14^{\circ}$ $35^{\circ}$ e $63^{\circ}$ DAI. Os bubalinos apresentaram parasitemia no $7^{\circ}, 14^{\circ}$, $35^{\circ}$ e $70^{\circ}$ DAI e os zebuínos apenas no $7^{\circ}$ e $28^{\circ}$ DAI, correspondendo aos picos de temperatura, em todas as espécies, sendo mais evidente em taurinos. Os parâmetros clínicolaboratoriais demonstraram que os taurinos foram mais sensíveis ao $\boldsymbol{T}$. gondii do que os zebuínos e estes não diferiram significativamente dos bubalinos, que tiveram aparente normalidade clínico-laboratorial.

Palavras-chave: toxoplasmose, Toxoplasma gondii, clínica, hematologia, bovino, búfalo.

\section{SUMMARY}

From each of the host species (Bos indicus, Bos taurus and Bubalus bubalis) three individual animals were orally inoculated with $2.0 \times 10^{5}$ sporulated Toxoplasma gondii oocysts Six other animals, being two from each of the host species, were kept as controls. Clinical abnormalities arising after the $3^{\text {rd }}$ day post-infection were hyperthermia, tachycardia, tachypnea, anorexia, prostration, nasal flowing and lacrimation. These signs were conspicuous in the taurine hosts, which also presented diarrhea, photophobia and conjunctivitis. It was possible to isolate $\boldsymbol{T}$. gondii from blood current from all species. In taurine, from $5^{\text {th }}$ day after inoculation up to the final of the experiment, the parasite was isolated from all the samples of blood obtained weekly, with exception of $14^{\text {th }}, 35^{\text {th }}$ and $6^{\text {rd }}$ day after inoculation. The buffalo cattle showed parasitemia at $7^{\text {th }}, 14^{\text {th }}, 35^{\text {th }}$ and $70^{\text {th }}$ day after inoculation and the zebu cattle only at $7^{\text {th }}$ and $28^{\text {th }}$ day after inoculation, corresponding to the peak of temperature, in all species, but more evident in taurines. The clinical-laboratorial parameters showed that the taurine was more sensible to $\boldsymbol{T}$. gondii than the zebu cattle and these did not differ significatively from the buffalo cattle that had apparently clinical-laboratorial normality.

Key words: toxoplasmosis, Toxoplasma gondii, clinical, haematology, bovine, buffalo.

\section{INTRODUÇÃO}

O Toxoplasma gondii Nicolle \& Manceux, 1909, é um coccídio intestinal dos felídeos que tem como hospedeiro intermediário diversas espécies de animais, inclusive o homem. Além das perdas reprodutivas em ruminantes (UNDERWOOD \& ROOK, 1992), a importância da toxoplasmose animal decorre do fato de os animais infectados servirem de fonte direta ou indireta de

\footnotetext{
${ }^{1}$ Doutorando do Curso de Pós-graduação em Medicina Veterinária, Parasitologia Veterinária, Departamento de Parasitologia Animal, Instituto de Biologia, Universidade Federal Rural do Rio de Janeiro. BR 465, Km 7, 23890-000, Seropédica, RJ. E-mail: oliveira@ufrrj.br. Autor para correspondência.

${ }^{2}$ Professor Titular, Departamento de Patologia (DP), Faculdade de Ciências Agrárias e Veterinária (FCAV), Campus de Jaboticabal, Universidade Estadual Paulista (UNESP).

${ }^{3}$ Mestrando do Curso de Pós-graduação em Medicina Veterinária, Patologia Animal, DP, FCAV, Campus de Jaboticabal, UNESP Recebido para publicação em 18.10.99. Aprovado em 21.11.00
} 
infecção ao homem. Justifica-se, portanto, o grande número de pesquisadores que têm se dedicado ao estudo desta importante zoonose nas duas últimas décadas, enfocando, principalmente, aspectos epidemiológicos, parasitológicos e clínicos da infecção (RUIZ \& FRENKEL, 1980; DUBEY, 1986; MAYER et al., 1987). Em síntese, T. gondii é capaz de causar severa doença em animais de produção tais como os caprinos, ovinos e suínos, provocando danos consideráveis, principalmente perdas reprodutivas, como abortamentos e elevada mortalidade de recém-nascidos (WORK et al., 1970; DUBEY, 1986; VIDOTTO \& COSTA, 1987; BRESCIANI, 1999). Embora o Neospora caninum seja recentemente, reconhecido como o maior causador de aborto em gado leiteiro (THILSTED \& DUBEY, 1989; BARR et al., 1991), não é descartado que o $\boldsymbol{T}$. gondii também possa causar abortamentos em bovinos.

Os principais sinais clínicos, observados em bovinos, por COSTA et al. (1977), no Brasil foram: hipertermia, distúrbios respiratórios, descargas ocular e nasal, hiperemia de conjuntiva e anorexia. Estes sinais clínicos foram também observados por MUNDAY (1978), FAYER \& FRENKEL (1979) e DUBEY (1983). Bubalinos infectados com oocistos do protozoário apresentaram, entre outros, os seguintes sinais: descarga nasal, lacrimejamento, anorexia, excitação, dispnéia e tenesmo (KALITA et al., 1978; GOUTAM et al., 1982).

Em face da importância econômica da bovinocultura no Brasil, este trabalho objetivou compilar dados clínicos e laboratoriais que permitam um melhor conhecimento da evolução da infecção, possibilitando um diagnóstico mais eficiente. Objetivou-se também, avaliar comparativamente as espécies Bos indicus, Bos taurus e Bubalus bubalis à susceptibilidade ao $\boldsymbol{T}$. gondii.

\section{MATERIAL E MÉTODOS}

Utilizou-se a cepa denominada "P", isolada de cão e gentilmente fornecida pelo Departamento de Parasitologia da USP de Ribeirão Preto, sendo mantida junto ao Centro de Pesquisas Parasitológicas (CPPAR), da Faculdade de Ciências Agrárias e Veterinárias de Jaboticabal (FCAVJ), Universidade Estadual Paulista (UNESP), através de sucessivas passagens em camundongos albinos. Para obtenção de oocistos foram utilizados seis gatos, SRD de quatro semanas de idade. Cada felídeo recebeu, via oral, aproximadamente 1500 cistos de T. gondii, provenientes de encéfalos de camundongos que foram infectados seis semanas antes. Os exames coprológicos, realizados com todo o volume de fezes emitido durante 24 horas pelos gatos, foram realizados diariamente, durante 15 dias consecutivos e os oocistos recuperados foram esporulados segundo DUBEY et al. (1972). As suspensões de oocistos foram previamente padronizadas (pré-inóculo) em solução salina a $0,9 \%$, sendo o tamanho do inóculo definido mediante a contagem de oocistos em câmara de Neubauer, de acordo com a técnica adotada por COSTA (1979).

Três animais de cada uma das espécies $\boldsymbol{B}$. indicus, B. taurus e $B$. bubalis, machos, pertencentes à faixa etária de quatro a sete meses, foram inoculados via oral, com $2,0 \times 10^{5}$ oocistos esporulados de $\boldsymbol{T}$. gondii. Um grupo de seis animais, de mesma idade e sexo, (dois de cada espécie) foi mantido como controle.

Durante três dias consecutivos antes da infecção experimental até o $70^{\circ}$ dia após inoculação (DAI), quando os animais foram sacrificados, pela manhã e à tarde, foram obtidos diariamente os seguintes dados clínicos dos ruminantes: temperatura retal, frequiências cardíaca e respiratória, exame dos linfonodos, aspecto de conjuntivas, apetite e outras observações, quando necessárias.

Os hemogramas foram realizados em todos os animais, por dois dias antes da inoculação e nos 1, 2, 3, 5 e 7 (DAI), sendo a partir de então as amostras colhidas semanalmente. Nos soros de todos os ruminantes, obtidos nos dois dias anteriores à inoculação, foram pesquisados anticorpos antiToxoplasma. As amostras de soro foram estocadas no laboratório a $-20^{\circ} \mathrm{C}$, e posteriormente submetidas à Reação de Imunofluorescência Indireta (RIFI), conforme técnica preconizada por CAMARGO (1964).

A quantidade de $10 \mathrm{~mL}$ de sangue dos bovinos contendo EDTA, foi centrifugado a 2000rpm durante 15 minutos. A camada leucocitária de cada amostra foi removida cuidadosamente por aspiração, diluída em $1,5 \mathrm{~mL}$ de solução salina e inoculada via intraperitoneal, em grupos de três camundongos albinos adultos, de ambos os sexos, pesando de 18 a 25 gramas de modo que cada camundongo recebesse $0,5 \mathrm{~mL}$. Os camundongos que morreram ou que tiveram aumento do volume abdominal, tinham o exsudato peritoneal examinados através de microscopia, para verificação da presença de $\boldsymbol{T}$. gondii. Os camundongos que sobreviveram, aos 42 dias de observação, foram sacrificados e o soro sangüíneo separado para pesquisa de anticorpos anti-Toxoplasma (RIFI), na diluição de 1:64, utilizando-se anti-imunoglobulina 
(anti-IgG) de camundondo conjugada ao isotiocianato de fluoresceína (F-6257-SIGMA-USA) segundo CAMARGO (1964), como também verificada a presença de cistos encefálicos.

Os dados das variáveis leucócito, eosinófilo, neutrófilo bastonete, neutrófilo segmentado, linfócito e monócito foram analisados em um delineamento inteiramente casualizado em esquema de parcelas subdivididas no tempo, tendo nas parcelas um esquema fatorial com seis tratamentos (três espécies e duas condições) e nas subparcelas as avaliações no tempo. Os dados da variável parasitemia foram analisados segundo um delineamento inteiramente casualizado com as espécies constituindo os tratamentos. Para todas as variáveis, utilizou-se a transformação $\sqrt{x+0,5}$.

\section{RESULTADOS}

Todos os animais apresentaram alterações em seus parâmetros fisiológicos, com variada intensidade. $\mathrm{Na}$ tabela 1, estão sintetizados os principais sinais clínicos observados nos ruminantes. Os dados referentes à temperatura retal, frequiências cardíaca e respiratória, são os que excederam ao maior parâmetro do grupo controle. Todos os soros dos animais obtidos nos dois dias anteriores à inoculação estavam negativos à RIFI, para pesquisa de anticorpos anti-Toxoplasma.

Não foram observados taquizoítos do T.gondii nos líquidos peritoneal dos camundongos examinados (determinação direta). Na tabela 2, estão registradas as determinações de parasitemia através da RIFI dos camundongos inoculados com camada leucocitária dos ruminantes dos três grupos experimentais (determinação indireta). Os valores médios para a parasitemia de B. indicus, B. taurus e B. bubalis foram 1, 3 e 1,33 respectivamente, sendo considerado a média de $\boldsymbol{B}$. taurus superior estatisticamente $(\mathrm{p} \leq 0,05)$ que B.indicus e $\boldsymbol{B}$. bubalis, pelo Teste de Tukey (Figura 1). Os valores do teste "F" para as células da série branca, hemácias, hemoglobina e hematócrito estão registrados na tabela 3. As médias das variáveis leucócito de B. indicus, B. taurus e B. bubalis foram $10.323,12.133$ e $12.471 / \mu \mathrm{L}$ respectivamente, sendo considerada a média de $\boldsymbol{B}$. indicus menor estatisticamente $(\mathrm{p} \leq 0,05)$, que a média de $\boldsymbol{B}$. bubalis pelo Teste de Tukey. As médias, para os mesmos ruminantes, da variável linfócitos foram 6.593, 8.647 e $8.588 / \mu \mathrm{L}$ respectivamente, sendo a média de B. indicus menor estatisticamente $(\mathrm{p} \leq 0,05)$, que as médias de $\boldsymbol{B}$. taurus e $\boldsymbol{B}$. bubalis pelo Teste de Tukey.

Tabela 1 - Sinais clínicos observados em Bos indicus, Bos taurus e Bubalus bubalis inoculados com 2,0 x $10^{5}$ oocistos de Toxoplasma gondii e do grupo testemunha.

\begin{tabular}{|c|c|c|c|c|c|c|c|c|c|c|}
\hline $\begin{array}{c}\text { Bovino } \\
\mathrm{n}^{\circ}\end{array}$ & Hipertermia & Taquicardia & Taquipnéia & Anorexia & Prostração & $\begin{array}{c}\text { Corrimento } \\
\text { Nasal }\end{array}$ & $\begin{array}{l}\text { Lacrimeja- } \\
\text { mento }\end{array}$ & Fotofobia & Diarréia & Ceratite \\
\hline \multicolumn{11}{|l|}{ B indicus } \\
\hline 07 & $(2-40)$ & $(4-8)$ e $(40-41)$ & - & - & $(3-10)$ & - & - & - & - & - \\
\hline 08 & $(2-47)$ & $(4-11)$ e $(38-41)$ & - & - & $(3-7)$ & - & - & - & - & - \\
\hline 09 & $(2-9)$ e (32-44) & $(3-7)$ e (39) & - & $(20-45)$ & $(4-7$ e $40-45)$ & - & - & - & - & - \\
\hline $06^{t}$ & - & - & - & - & - & - & - & - & - & - \\
\hline $10^{t}$ & - & - & - & - & - & - & - & - & - & - \\
\hline Média & $(2-44)$ & $(4-8$ e $39-41)$ & - & - & $(3-7)$ & - & - & - & - & - \\
\hline \multicolumn{11}{|l|}{ B. taurus } \\
\hline 16 & $(4-15)$ e $(44-70)$ & $(4-9)$ & $(4-9)$ & $(4-10)$ & $(4-10)$ & - & $(7-12)$ & $(4-10)$ & $(8-11)$ & $(7-12)$ \\
\hline 17 & $(2-9)$ e $(45-70)$ & $(4-8)$ & $(4-12) \mathrm{e}(25-26)$ & $(4-8)$ & $(4-10)$ & - & $(7-12)$ & $(4-10)$ & $(8-10)$ & $(7-12)$ \\
\hline 18 & $(3-10)$ e $(43-70)$ & $(3-4)$ & $(4-12)$ e $(24-26)$ & $(5-10)$ & $(4-8)$ & - & $(7-12)$ & $(4-10)$ & $(9-10)$ & $(7-12)$ \\
\hline $19^{\mathrm{t}}$ & - & - & - & - & - & - & - & - & - & - \\
\hline $20^{t}$ & - & - & - & - & - & - & - & - & - & - \\
\hline Média & $(3-14)$ e $(43-70)$ & $(5-6)$ & $(4-9)$ e (24-26) & $(4-9)$ & $(4-10)$ & - & $(7-12)$ & $(4-10)$ & $(8-11)$ & $(7-12)$ \\
\hline \multicolumn{11}{|c|}{ B. bubalis } \\
\hline 687 & $(2-5)$ e (51-68) & $(4-7)$ & - & - & - & $(2-7)$ & - & - & - & - \\
\hline 691 & $(2-7)$ e (61-68) & $(2-6)$ & - & - & - & - & $(4-6)$ & - & - & - \\
\hline 695 & (3-9) e (58-69) & 4 & $(4-6)$ & - & - & $(2-6)$ & - & - & - & - \\
\hline $693^{\mathrm{t}}$ & - & - & - & - & - & - & - & - & - & - \\
\hline $690^{t}$ & - & - & - & - & - & - & - & - & - & - \\
\hline Média & $(3-8)$ e (61-68) & $(3-6)$ & $(3-8)$ & - & - & - & - & - & - & - \\
\hline
\end{tabular}

( ) Número entre parênteses referem-se a dias pós-inoculação.

${ }^{\mathrm{t}}$ Testemunho.

Ciência Rural, v. 31, n. 4, 2001. 
Tabela 2 - Determinação indireta da parasitemia em Bos indicus, Bos taurus e Bubalus bubalis inoculados via oral com 2,0 x $10^{5}$ oocistos de Toxoplasma gondii e nos animais testemunhos.

\begin{tabular}{|c|c|c|c|c|c|c|c|c|c|c|c|c|c|c|c|c|}
\hline \multirow{2}{*}{$\begin{array}{c}\text { Número do } \\
\text { Bezerro }\end{array}$} & \multicolumn{16}{|c|}{ Parasitemia (dias após inoculação) ${ }^{\mathrm{a}}$} \\
\hline & -2 & -1 & 1 & 3 & 5 & 7 & 14 & 21 & 28 & 35 & 42 & 49 & 56 & 63 & 70 & Total \\
\hline \multicolumn{17}{|l|}{ Bos indicus } \\
\hline 7 & - & - & - & - & - & - & - & - & Ps & - & - & - & - & - & - & 1 \\
\hline 8 & - & - & - & - & - & - & - & - & Ps & - & - & - & - & - & - & 1 \\
\hline 9 & - & - & - & - & - & Ps & - & - & - & - & - & - & - & - & - & 1 \\
\hline $06^{\mathrm{t}}$ & - & - & - & - & - & - & - & - & - & - & - & - & - & - & - & 0 \\
\hline $10^{\mathrm{t}}$ & - & - & - & - & - & - & - & - & - & - & - & - & - & - & - & 0 \\
\hline Total & - & - & - & - & - & 1 & - & - & 2 & - & - & - & - & - & - & 3 \\
\hline \multicolumn{17}{|l|}{ Bos taurus } \\
\hline 16 & - & - & - & - & - & - & - & - & Ps & - & Ps & Ps & Ps & - & - & 4 \\
\hline 17 & - & - & - & - & Ps & Ps & - & Ps & - & - & - & - & - & - & - & 3 \\
\hline 18 & - & - & - & - & - & - & - & - & Ps & - & - & - & - & - & Ps & 2 \\
\hline $19^{\mathrm{t}}$ & - & - & - & - & - & - & - & - & - & - & - & - & - & - & - & 0 \\
\hline $20^{t}$ & - & - & - & - & - & - & - & - & - & - & - & - & - & - & - & 0 \\
\hline Total & - & - & - & - & 1 & 1 & - & 1 & 2 & - & 1 & 1 & 1 & - & 1 & 7 \\
\hline \multicolumn{17}{|l|}{ Bubalus bubalis } \\
\hline 687 & - & - & - & - & - & - & - & - & - & Ps & - & - & - & - & - & 1 \\
\hline 691 & - & - & - & - & - & - & - & - & - & - & - & - & - & - & Ps & 1 \\
\hline 695 & - & - & - & - & - & Ps & Ps & - & - & - & - & - & - & - & - & 2 \\
\hline $693^{t}$ & - & - & - & - & - & - & - & - & - & - & - & - & - & - & - & 0 \\
\hline $690^{t}$ & - & - & - & - & - & - & - & - & - & - & - & - & - & - & - & 0 \\
\hline Total & - & - & - & - & - & 1 & 1 & - & - & 1 & - & - & - & - & 1 & 4 \\
\hline
\end{tabular}

a Camundongos inoculados pela via intraperitoneal com camada leucocitária dos bovinos e bubalinos.

Ps = RIFI para toxoplasmose positiva ( $\geq 1: 64)$ em camundongos inoculados.

${ }^{\mathrm{t}}$ Testemunha.

\section{DISCUSSÃO}

Os exames clínicos, hematológicos e sorológicos, realizados nos dois dias anteriores a inoculação de $\boldsymbol{T}$. gondii, confirmaram a sanidade dos animais utilizados experimentalmente. As alterações clínicas contidas na tabela 1 , exceto o sinal clínico de fotofobia, assemelham-se àqueles descritos por COSTA et al. (1977), FAYER \& FRENKEL (1979), e DUBEY (1983), em B. taurus experimentalmente infectados com oocistos de $\boldsymbol{T}$. gondii. Os sinais clínicos ocorridos nos bubalinos experimentais, foram praticamente os mesmos encontrados por KALITA et al. (1978) e GOUTAM $\boldsymbol{e t}$ al. (1982), exceto a excitação verificada por estes autores e não observada neste experimento. A infecção experimental de $\boldsymbol{B}$. indicus com oocistos de Toxoplasma não foi observada e os taurinos apresentaram sintomatologia mais grave do que os zebuínos e bubalinos. Os bubalinos mostraram-se menos susceptíveis clinicamente ao $T$. gondii do que às outras espécies de bovinos estudadas.

As contagens de hemácias, os valores médios de hemoglobina e de hematócrito permaneceram dentro dos parâmetros normais para cada espécie em estudo. Entretanto, os dados parecem indicar uma interação espécie $\mathrm{X}$ tempo significativa $(p \leq 0,01)$. Uma análise do desdobramento dessa interação poderia indicar as diferenças entre espécie ao longo do tempo. Esta variabilidade entre raças e faixas etárias já havia sido discutida, em bovinos, por COSTA VAL et al. (1971). A não significância das interações espécie X condição e condição $\mathrm{X}$ tempo, para hemácias e hematócrito, indicaram que as médias dos animais inoculados e controles diferiram significativamente $(\mathrm{p} \leq 0,01)$. Na variável hemoglobina, não houve diferença significativa entre inoculados e controles. A leucocitose ocorreu entre os dias 14 e 21 e entre o $35^{\circ}$ e $63^{\circ}$ DAI. A interação condição X tempo para esta variável foi significativa $(p \leq 0,01)$, indicando uma certa correlação entre inoculados e controles com o transcorrer do tempo. A não significância ( $\mathrm{p}$ > $0,05)$ das interações condição $X$ tempo, espécie $X$ tempo, espécie $X$ condição e o fator condição permitiram inferir que a significância $(\mathrm{p} \leq 0,05)$ do fator espécie é devida a B. indicus e B. bubalis. Os neutrófilos segmentados e linfócitos foram as células responsáveis pelo aumento do número global de leucócitos em taurinos e bubalinos. Em B. indicus, a 
Tabela 3 - Valores do teste F para as variáveis hemácias (He), Hemoglobina (Hb), hematócrito (Ht), leucócito (Le), eosinófilo bastonete (Nb), neutrófilos segmentados (NS), linfócitos (Linf) e monócitos (Mon).

\begin{tabular}{|c|c|c|c|c|c|c|c|c|c|}
\hline Estatísticas & $\mathrm{He}$ & $\mathrm{Hb}$ & $\mathrm{Ht}$ & $\mathrm{Le}^{\mathrm{r}}$ & $\operatorname{Eos}^{r}$ & $\mathrm{Nb}^{\mathrm{r}}$ & $\mathrm{Ns}^{\mathrm{r}}$ & Linf & $\operatorname{Mon}^{r}$ \\
\hline \multicolumn{10}{|l|}{ Parcelas } \\
\hline $\begin{array}{r}\text { F para: } \\
\text {. Espécie }\end{array}$ & $8,39 * *$ & $3,75^{\mathrm{NS}}$ & $8,30 * *$ & $4,73^{*}$ & $0,92^{\mathrm{NS}}$ & $0,16^{\mathrm{NS}}$ & $0,67^{\mathrm{NS}}$ & $8,26 * *$ & $12,4 * *$ \\
\hline . Condição & $9,52 *$ & $4,79^{\mathrm{NS}}$ & $12,7 * *$ & $1,04^{\mathrm{NS}}$ & $0,00^{\mathrm{NS}}$ & $0,16^{\mathrm{NS}}$ & $2,91^{\mathrm{NS}}$ & $5,71 *$ & $0,31^{\mathrm{NS}}$ \\
\hline Espécie $\mathrm{x}$ condição & $2,49^{\mathrm{NS}}$ & $2,16^{\mathrm{NS}}$ & $2,31^{\mathrm{NS}}$ & $1,97^{\mathrm{NS}}$ & $2,27^{\mathrm{NS}}$ & $0,28^{\mathrm{NS}}$ & $0,43^{\mathrm{NS}}$ & $3,84^{\mathrm{NS}}$ & $1,79^{\mathrm{NS}}$ \\
\hline. $\mathrm{CV}$ & $21,09 \%$ & $18,45 \%$ & $19,27 \%$ & $18,45 \%$ & $177,6 \%$ & $212,1 \%$ & $59,50 \%$ & $20,5 \%$ & $87,53 \%$ \\
\hline \multicolumn{10}{|l|}{ Subparcelas } \\
\hline $\begin{array}{r}\text { F para: } \\
\text {. Tempo }\end{array}$ & $6,85 * *$ & $13,8 * *$ & $6,37 * *$ & $4,58 * *$ & $0,98^{\mathrm{NS}}$ & $0,86^{\mathrm{NS}}$ & $4,69 * *$ & $3,22 * *$ & $5,90 * *$ \\
\hline Espécie x tempo & $3,66 * *$ & $3,85 * *$ & $2,15 * *$ & $1,35^{\mathrm{NS}}$ & $1,60^{\mathrm{NS}}$ & $0,65^{\mathrm{NS}}$ & $1,78 *$ & $0,76^{\mathrm{NS}}$ & $4,07 * *$ \\
\hline . Condição. $x$ tempo & $0,86^{\mathrm{NS}}$ & $0,73^{\mathrm{NS}}$ & $0,84^{\mathrm{NS}}$ & $5,8 * *$ & $0,83^{\mathrm{NS}}$ & $1,26^{\mathrm{NS}}$ & $4,15 * *$ & $3,74 * *$ & $0,68^{\mathrm{NS}}$ \\
\hline Espécie $\mathrm{x}$ condição $\mathrm{x}$ tempo & $2,15 * *$ & $1,36^{\mathrm{NS}}$ & $0,70^{\mathrm{NS}}$ & $0,69^{\mathrm{NS}}$ & $0,75^{\mathrm{NS}}$ & $0,92^{\mathrm{NS}}$ & $1,25^{\mathrm{NS}}$ & $0,64^{\mathrm{NS}}$ & $1,56^{\mathrm{NS}}$ \\
\hline . CV & $10,19 \%$ & $10,86 \%$ & $10,22 \%$ & $7,61 \%$ & $116,5 \%$ & $165,9 \%$ & $14,41 \%$ & $8,71 \%$ & $71,11 \%$ \\
\hline
\end{tabular}

* Significativo a $5 \%(\mathrm{p}<0,05)$.

** Significativo a $1 \%(\mathrm{p}<0,01)$

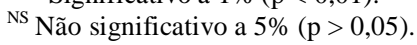

${ }^{\mathrm{r}}$ Dados transformados por $\sqrt{x+0,5}$.

leucocitose foi devido à neutrofilia. Estes resultados diferem de COSTA et al. (1977) e COSTA (1979) que evidenciaram apenas aumento de neutrófilos bastonetes. Embora etiologicamente distinta, a leucocitose observada nos três experimentos, possivelmente indica que estaria ocorrendo, nesta fase, uma disseminação ou localização e proliferação do parasito em novos locais do organismo, visto que a principal função dos neutrófilos é a fagocitose. Estas células estão relacionadas, também, com as reações inflamatórias secundárias a agentes invasores dos tecidos, doenças imunomediadas e necrose tecidual inespecíficas, como ocorre em outros processos patológicos (COLES, 1974). O aumento de linfócitos está relacionado, possivelmente, a uma hiperplasia dos folículos dos órgãos linfóides, principalmente baço e linfonodos de bovinos nas infecções pelo $\boldsymbol{T}$. gondii
(OLIVEIRA, 1997). As contagens de neutrófilos segmentados, transformadas por raiz quadrada, mostram uma interação espécie $X$ tempo significativa $(p \leq 0,05)$ e condição $X$ tempo também significativa $(\mathrm{p} \leq 0,01)$, indicando um comportamento diferente de cada espécie e condição ao longo do tempo. A significância da interação condição $X$ tempo $(\mathrm{p} \leq 0,01)$ não permite comentar a condição e o tempo isoladamente. Entretanto, a não significância de espécie $X$ tempo e espécie $X$ condição indica que o número de linfócitos de $\boldsymbol{B}$. indicus foi significativamente menor quando comparado com $\boldsymbol{B}$. taurus e B. bubalis, os quais não diferiram entre si. A significância entre espécie $X$ tempo $(p \leq 0,01)$, para monócitos, mostra um comportamento diferenciado entre as espécies ao longo do tempo. Todos os fatores para eosinófilos e neutrófilos bastonetes foram não significativos ( $p>0,05)$, o que pode ser devido à grande variabilidade destes tipos celulares (Tabela 3).

A infecção toxoplásmica diagnosticada através de determinações parasitêmicas ficou comprovada em todas os animais inoculados (Tabela 2). $\boldsymbol{B}$. indicus apresentou dois surtos parasitêmicos por $\boldsymbol{T}$. gondii, no sétimo e no $28^{\circ}$ DAI. De um B. taurus a parasitemia foi detectada no quinto, sétimo e $21^{\circ}$ DAI, em outro no $28^{\circ}, 42^{\circ}, 49^{\circ}$ e $56^{\circ}$ DAI e no terceiro no $28^{\circ}$ e $70^{\circ}$ DAI. Quatro surtos

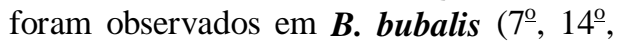
$35^{\circ}$ e $70^{\circ}$ DAI). Os resultados mostram que B. taurus difere, nesta variável, estatisticamente $(\mathrm{p} \leq 0,05)$ de $\boldsymbol{B}$. indicus e
Figura 1 - Box-Plot da variável parasitemia de Bos indicus, Bos taurus e Bubalus bubalis inoculados via oral com $2 \times 10^{5}$ oocistos de Toxoplasma gondii. 
B. bubalis (Figura 1). Fica evidente, portanto, que o maior número de surtos parasitêmicos ocorreu nos taurinos, inclusive na fase crônica da infecção, ocasião em que todos os três animais apresentavamse aparentemente em boas condições de saúde (Tabela 2). Este fato foi observado também por COSTA et al. (1977) em B. taurus. Neste experimento, tal fato ocorreu em um bubalino, no qual se isolou o parasito do sangue no $70^{\circ}$ DAI. No zebuíno $\boldsymbol{T}$. gondii foi isolado somente durante a fase aguda da doença, entretanto, estes se comportaram como os bubalinos quanto ao número de isolamentos (Tabela 2 e Figura 1).

\section{CONCLUSÃO}

Os oocistos de $\boldsymbol{T}$. gondii produziram transtornos clínicos em todas as três espécies estudadas, sendo mais evidentes em B. taurus. Os surtos parasitêmicos corresponderam aos picos de temperatura obtidos em todas as espécies, principalmente em taurinos. Os valores médios hematológico estiveram dentro da normalidade para as três espécies estudadas, tendo os zebuínos menor número de alterações hematológicas que taurinos e bubalinos.

\section{REFERÊNCIAS BIBLIOGRÁFICAS}

BARR, B.C., ANDERSON, M.L., DUBEY, J.P., et al. Neospora-like protozoal infections associated with bovine abortions. Vet Pathol, v.28, p.110-116, 1991.

BRESCIANI, K.D.S., COSTA, A.J., TONILlO, G.H., $\boldsymbol{e} \boldsymbol{t}$ al. Experimental toxoplasmosis in pregnant bitches. Vet Parasitol, v.86, p.143-145, 1999.

CAMARGO, M.E. Improved tecnique of indirect imunofluorescence for serological dianosis of toxoplasmosis. Rev Inst Méd São Paulo, v.6, n.3, p.117-118, 1964.

COLES, E.H.. Veterinary clinical pathology. Philadelphia : Saunders, 1974. Leukocytes: p.40-98.

COSTA, A.J. Toxoplasmose congênita natural em bovinos e infecção experimental de vacas gestantes com oocistos de T. gondii. São Paulo - SP, 1979. 88p. Tese (Doutorado em Parasitologia) - Faculdade de Medicina Veterinária, Parasitologia Veterinária, USP, 1979.

COSTA, A.J., ARAUJO, F.G., COSTA, J.O., et al. Experimental infection of bovines with oocysts of Toxoplasma gondii. J Parasitol, v.63, n.2, p.212-214, 1977.
COSTA VAL, V.P., PESSOA, J.M., FERREIRA NETO, J.M. Variações no hemograma de bezerros durante os primeiros estágios de vida após o nascimento. Arq Esc Vet Belo Horizonte, v.23, p.291-296, 1971.

DUBEY, J.P. Distribuition of cysts and tachyzoites in calves and pregnant cows inoculated with Toxoplasma gondii oocyst. Vet Parasitol, v.13, n.199-201, 1983.

DUBEY, J.P. Toxoplasmosis. J Am Vet Med Assoc, v.189, n.2, p.166-179, 1986.

DUBEY, J.P., SWAN, G.V., FRENKEL, J.K. A simplified method for isolation of Toxoplasma gondii from the faeces of cats. J Parasitol, v.58, n.5, p.1005-1006, 1972.

FAYER, R., FRENKEL, J.K. Comparative infectivity for calves of ocysts of feline coccidai: Besnoitia, Hammondia, Cytoisospara, Sarcocystes and Toxoplasma. J Parasitol, v.6 n.5, p.756-762, 1979.

GOUTAM, O.P., CHHABRA, M.B., GUPTA, S.L., et al. Experimental toxoplasmosis in buffalo calves. Vet Parasitol, v.11, n.4, p.293-299, 1982.

KALITA, C.C., GAUTAM, O.P., BHARDWAJ, R. Experimental toxoplamosis in buffalo-calves. Indian J Publ Health, v.22, n.4, p.325, 1978.

MAYER, H.F., MARDER, G., PEIRETTI, H.A. Prevalence of Toxoplasma antibodies in man and animals in North East Argentina. Vet Arg, v.5, p.889-893, 1987.

MUNDAY, B.L. Bovine toxoplasmosis: experimental infections. Inst J Parasitol, v.8, n.4, p.285-288, 1978.

OLIVEIRA, F.C.R. Infecção experimental de Bos indicus, Bos taurus e Bubalus bubalis com oocistos de Toxoplasma gondii. Estudo comparativo. Jaboticabal - SP, 1997. 92p. Dissertação (Mestrado em Patologia Animal) - Curso de Pósgraduação em Medicina Veterinária de Faculdade de Ciências Agrária e Veterinária, Campos de Jaboticabal/UNESP, 1997.

RUIZ, A., FRENKEL, J.K. Toxoplasma gondii in Costa Rica cats. Am J Trop Med Hyg, v.29, p.1150-1160, 1980.

THILSTED, J.P., DUBEY, J.P. Neosporosis-like abortions in a herd of dairy catthe. J Vet Diagn Invest, v.1, p.205-209. 1989.

UNDERWOOD, W.J., ROOK, J.S. Toxoplasmosis infection in sheep. Comp Cont Educ Pract Vet, v.14, p.1543-1549, 1992.

VIDOTTO, O., COSTA, A.J. Toxoplasmose experimental em porcas gestantes. I. Observações clínicas e hematológicas. Arq Bras Med Vet Zoot, v.39, p.623-639, 1987.

WORK, K., ERIKSEN, L., FENNESTAD, K.L. Experimental toxoplasmosis in pregnant sows. Acta Path Microbiol Scand, Section B, v.78, p.129-134, 1970. 